\title{
System Estimation of Russian Regions' innovational development
}

\author{
Aleksey Simonov \\ Volgograd State Technical University, \\ Department of Economics and Management \\ Chair of Information Systems in Economics \\ Volgograd, Russia \\ absimonov@gmail.com
}

\author{
Irina Tarasova \\ Volgograd State Technical University, \\ Department of Economics and Management \\ Chair of Applied Mathematics \\ Volgograd, Russia \\ tarasova.irina.aleks@gmail.com
}

\author{
Irina Simonova \\ Volgograd State Technical University, \\ Department of Economics and Management \\ Chair of Applied Mathematics \\ Volgograd, Russia \\ simonova-vstu@mail.ru
}

\begin{abstract}
The article is devoted to the issues of optimizing and the innovational development managing in Russia's regions based on the statistical methods and the theory of decisionmaking. The existing innovation indices were studied and their benefits and drawbacks are given. We offer the methodology of the system estimation of hierarchically structured innovative activity indicators, which is peculiar for the preliminary statistical analysis of the evaluated parameters. It is indicated that the majority of the characteristics of innovation process in the Russian Federation obeys log-normal distribution, which implies the logarithms of empirical data for the correct use of the mathematical tool of the theory of decision-making and obtaining results of easily comprehensible form. We clustered Russian regions into four clusters which represent the scientific and technical potential, the level of innovation activity and the state of innovations' activity sphere. The results of the clustering have enabled us to define three leading regions which stand out due to their high-quality innovation activity. What is common for many other regions is that the ineffective unleashing interferes with their high innovation potential. Thus, it is crucial to develop the infrastructure of the commercialization of innovations in the Russian regions. According to the cluster peculiarities we offer the ways to increase the innovational development effectiveness in regions based on the received results.
\end{abstract}

Keywords - innovations, system estimation, statistical analysis, clustering, innovational development

\section{INTRODUCTION}

Studying of the innovations and innovational process is one of the most actual problems of economics. Innovations determine significantly the way of life in any region. So we set the goal to study the innovational development of Russia's regions. However, the estimation of the innovations is difficult. The first problem is systemic nature of innovational processes that consist of $\mathrm{R} \& \mathrm{D}$, commercialization, and the diffusion of innovation. So, we propose the method of system estimation, that studies all aspects of these processes and identifies problems that can occur at any stage of the creation of innovation. This method is theory-based on hierarchal structured ideas of innovation theory.

The key point of this method is statistical analysis of the studied data. The great problem of studying innovation is "bad" data. The same product may be called innovative in one region and common in another. It may be difficult to appraise the value of innovation and so on. So our method is pointed to determinate "bad" data and undercut their influence on the result. This is a unique methodic in this field and can highly increase the accuracy of the results.

Moreover, we used a clustering method to interpret the results of the calculations. This method has not been used systematically in such studies. However, it is extremely useful as it helps observe factors that determine innovation processes in the particular region.

Innovational development is the most important component of the regional system and regional development on the whole. A lot of examples show that underrun in scientific and technical development leads to underrun in the economic, social, and other spheres. There are also opposite examples, the most vivid of which is the Silicon Valley in California, which innovational products became the basis of the successful development both at the regional and global levels. Innovational development leads to the rise of the quality of life, development of the economy, provides 
socioeconomic stability, and the rise of territories competitiveness [1]. Thus, management of a region's innovational development is the main component of the successful strategic management of a region on the whole.

Unfortunately, the efficient management of the innovational process faces a lot of difficulties, the majority of which origins in the complexity of this process. Obviously, the management of heterogeneous components of the innovational process at the level of a whole region is rather difficult, and it leads to the wish to reduce the innovational process to applied R\&D and design works. This, in turn, leads to a range of problems, related to disproportions in the innovational process - in particular, insufficient consistency and effectiveness of commercialization of innovations in many regions of the Russian Federation. The systemic management of various aspects of the innovative activity at the regional level requires the presence of systemic indicators and methods of evaluation of the innovative activity as a tool for planning and control of measures for effective management of the innovational development. This, in turn, influences the process of synthesis of the structure and further functioning of the regional economy as a complex system.

The issues of the development of the aggregate systemic indicator for evaluating the innovative activity are very topical [2] and are studied in a range of international and Russian rankings of the innovational activity [1][3][4][5][6][7][8].

These rankings differ in the quantity and level of substantiation of the indicators of state of regions' innovative activity, which are taken into account in the ranking. Generally, for the evaluation of the offered indicators the data of the official statistics is used, and sometimes - the results of an expert evaluation. Using the data of the official statistics allows to increase the authenticity and quality of the received indicators.

Despite all the advantages of these rankings, they have several drawbacks which reduce their value during the management of the innovational development. Firstly, it is the high sensitivity to distinguished observations. Secondly, these methodologies are based on the a priori supposition on the correctness of statistical data. This peculiarity can distort the value of the ranking indicators. Thirdly, while compiling the rankings, the peculiarities of distribution of innovational indicators for the regions are not considered which leads to a large gap between the leading regions and their main mass, which is compensated by rather artificial technical methods. The purpose of this study is to develop a methodology of the estimation of the innovational processing without these downsides, what will increase the validity of the results of the research. In particular, in this study:

- We offer a range of methodologies which allow to increase the quality of the received ranking indicators by the application of the statistical analysis methods;

- We calculate the system of Russia's regions innovational activity indicator. It is performed on the basis of the offered methodologies taking into account the distinguished values and possible distortion of information;
- We made interpretation of the received results, that is based on clustering of Russia's regions into four clusters. Qualitative peculiarities of the distinguished clusters are described in this issue, and conclusions on the possibility of managerial influence for improvement of innovational development in Russia's regions are made.

\section{METHODS}

In this study we used literary and graphical analysis methods, methodologies a creating an integral index and the cluster analysis which described below. To prove hypothesis of the compliance between the empirical data and the theory of distribution for the preliminary data (that are used when assessing intefral index) analysis the statistical methods were used. Statgraphics was used to produce estimates.

\section{CREATION OF THE INNOVATION INDICES SYSTEM}

To create the system of indices which will are analysed in decision-making is a complex hierarchical process. We suggest to define three index groups according to the logic of of the analysed innovation development process. Each index will be decompiled into indicators. The upper level indicators are those which describe the state of region's innovation sphere (education system, Internet connection, investment activity); indicators of region's scientific and technical potential; and indicators of region's innovation activity. Each group indicators were created according to the experince of the studying of other regions as well as according to the common logic of studied processes. Additionally, we suggest the fourth indicator group which includes the quality of the statistical data. and the indicators which consider the stability and predictability of region's innovation development are also suggested. Now they include the number of indicators for which there is no information, and the number of indicators for which the information stands out unbelievably compared to other regions. In the future this list of indicators can be expanded with the number of indicators which dynamics underwent substancial change and with the account of the consistency of the data of a particular region through econometric model of the relations between different stages of innovation activity in the Russian regions. The full list of used indicators is represented in [6].

\section{ANALYSIS OF THE LAWS OF DISTRIBUTION OF INNOVATIVE ACTIVITIES' INDICATORS IN THE RUSSIAN REGIONS}

One of the key differences between the applied methodology and other integral indicators of innovative activity is the fact that the gathered data was analyzed for the correspondence to the distribution laws. This conforms to the general logic of statistical analysis of data. We offered hypotheses on the possible normality or abnormality of the gathered data. For the verification of the correspondence to the laws of distribution, we used the criteria of KolmogorovSmirnov and Shapiro-Wilk. In most cases we found out that a normal or lognormal law can be applied for all the mass of the data or after the deletion of a small number of distinguished regions. However, for most indicators large deviations could 
be explained by certain qualitative characteristics of the regions.

To bring the index indicators down to the comparable type and to eliminate the asymmetry of distribution, it is necessary to bring the lognormally distributed totalities down to a normal form by calculating the logarithms from the parameters' values. The selected method allows to bring all the data down to the comparable form by statistical methods and separating the innovational development from corresponding economic effects, the scale effect, in particular.

After bringing the indicators' distribution to a normal form we distinguished and excluded the distinguished indicators. Determination of the distinguished indicators has sense from the point of view of managing the innovational development at the level of regions. The region's indicators that stand out (especially the indicators that are below the expected values) allow to determine the weak spots in region's development, predicting threats for its stable strategic development, and taking measures for their elimination.

The regions determined as standing out for each indicator were set separately. For each region it was calculated how many times it was assigned to the distinguished, and to which side the deviations were. After that, the regions were returned into totality, but values of the attribute were assigned minimal values of indicators of quality with the regions that were left in the totality.

The indicators of the quality of information and systematicity of indicators of innovational activity (distinguished into sub-group 4) were set separately. The number of the indicators in which the region differs from the main totality, was included into the indicator 4.1 "Distinguished values of the indicator". The number of indicators the value of which is absent for this region were assigned into the indicator 4.2 "Lack of information for certain indicators of innovational activity". It should be noted that it is possible to supplement this set by the indicator of predictability of dynamics of innovational processes and the indicator of the quality of interconnection of innovational processes.

\section{Creation of the Aggregated Evaluation of INNOVATIVE ACTIVITY}

The received system of indicators was used for obtaining the final aggregated evaluation. At first, the values of each indicator for each region were formed:

$$
y_{i r}=\frac{x_{i r}-\tilde{x}_{i, \min }}{\tilde{x}_{i, \max }-\tilde{x}_{i, \min }}
$$

where $i$ - No. of indicator; $r-$ No. of region; $y_{i r}$ - normed value of $i$-th indicator which takes value from 0 (minimum value of indicators among all regions) to 1 (maximum value of indicators among all regions); $x_{i r}$ - corrected value of $i$-th indicator, received in the course of preliminary analysis; $\tilde{x}_{i, \max }, \tilde{x}_{i, \min }-$ accordingly, minimum and maximum values of $i$-th corrected indicator among all regions.

It should be noted that this approach is widely used in the modern statistics for norming the indicators, ensuring high compatibility even of qualitatively different evaluations.

The received normed values were aggregated into subindices of the state of the innovational sphere, scientific, and technical potential and innovational activity. The formula of unweighted direct average was used for that:

$$
I_{r}=\frac{1}{n_{r}} \sum_{i=1}^{n_{r}} y_{i r}
$$

where $I_{r}$ - the value of sub-index for region $r ; n_{r}$ - number of indicators which are taken into account within this subindex for the region $r ; y_{i r}$ - normed value of $i$-th indicator, which takes values from 0 to 1 .

For calculating the generalized indicator for each region we used the weighted additive aggregation with amendment $\mathrm{Kr}$, which takes into account the distinguished data and the lack of information.

$$
C I_{r}=\left(\frac{1}{n_{r}} \sum_{i=1}^{n_{r}} y_{i r}\right)-\frac{1}{n_{r}} K r
$$

The calculated indicator can be interpreted as an average value of the indices that characterize various aspects of innovative activity. Indicator $K r$ reduces the value of the resulting indicator in case of the lack of information or if a low quality of information is supposed. Specific values of the indicators received for the regions are available in the annex.

\section{CluUstering OF REGIONS}

To study the peculiarities of innovation activity in the Russian regions for the purpose of qualitative improvement of management we performed clustering of regions according to the values of sub-indices

Clustering was performed with the Statgraphics program. The parameters were the values of three sub-indices received in the previous calculations. The measure of distance (differences in the values of sub-indices) between the regions was the Euclidean distance, and the clustering was performed with the Ward's method. As a result, we distinguished four clusters. Figure 1 shows the process of determination of clusters is shown, and Figure 2 shows the graphic 3D presentation of the results of clustering.

As we can see, the regions were distributed according to the clusters in the following way:

Cluster A includes three most innovational and developed regions (Moscow, St. Petersburg, and the Republic of Tatarstan), which are peculiar for high indicators of innovative activity (average value -0.797 ) and the state of innovational 
sphere (0.806). Scientific and technical potential is also very high (average value -0.638 ), but several regions of cluster B have higher values of scientific and technical potential than the values of Tatarstan and St. Petersburg. These regions are a driving force of the Russian innovational activity, they have a long history of scientific \& technical activity which goes back to the 18th - 19th centuries, and have large support from federal bodies.

Fig. 1. Dendrogram of clustering of regions of the Russian Federation according to the indicators of innovative activity into four clusters.

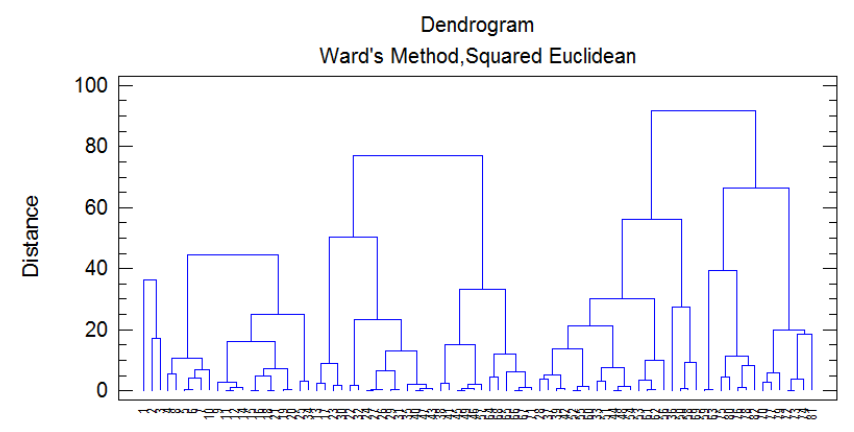

Cluster B includes 18 innovational and developed regions with a high indicator of scientific and technical potential (average value of the index -0.571 , which is below the value for cluster A by 0.067), but they realize their potential less effectively than the regions of cluster A (average value of index 0.660, the difference between cluster A of 0.137). The main difference between the clusters is in the less developed innovational sphere (average value -0.468 ). The data of the clustering allows to state that these regions, while having large innovational potential and good current indicators of innovational development, should pay special attention to the development of various spheres of the innovational infrastructure, as this (and, probably, lesser federal support) is the main factor of their underrun from the regions of cluster $\mathrm{A}$ and may - under unfavorable conditions - lead to a technological underrun from other Russian regions.

Fig. 2. Clustering of regions according to the indicators of innovational development.

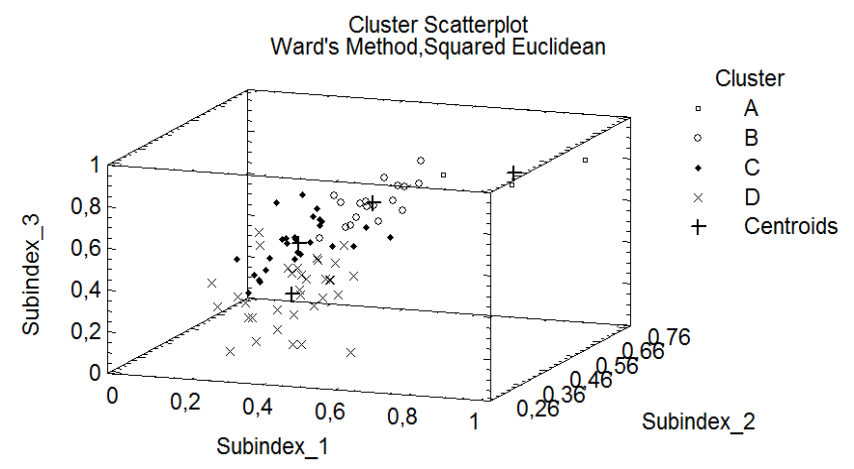

Cluster C includes 27 regions which differ dramatically according to their indicators of innovational activity, but also are behind cluster B according to the most indicators. Having medium innovational indicators, this cluster features relatively high innovative activity (average value of sub-index - 0.584) and a good state of the innovational sphere (average value of sub-index 0.967). The main problem of the innovational activity of this cluster is weak indicators of scientific and technical potential (average value -0.383 ). The data of clustering shows the importance of the development of the innovational sphere at the modern stage of Russia's development, as this indicator allows the regions of the cluster to achieve high innovational activity even with low potential. It is also possible to recommend activation of innovational policy, with special attention paid to development and full use of scientific and technical potential of the region.

Cluster D includes 34 regions which also differ drastically according to their indicators of the innovational activity. They are united by the presence of a certain scientific and technical potential (average value of sub-index 0.408 which is higher than for cluster B), which, however, is used insufficiently systemically and not in full (average value of sub-index of innovative activity is 0.320 which is by 1.5 times smaller than for cluster B). So, as we can see, the same as with cluster B, weak usage of the existing scientific and technical potential is caused by insufficient attention to the development of the innovational sphere (average value of the corresponding subindex 0.361). To provide a sustainable innovational development of these regions special attention should be paid to the development of the innovational sphere, including creation of information channels, support for fundamental research and education, renovation of the main funds, and development of financial and economic literacy (if such a goal is set by the management).

\section{RESULTS}

The main result of this study is valid methodology os systematic estimation with the preliminary data analysis. The clusters derived accorging to the indices and sub-indices do not have considerable assymetry and are not distinguished dramatically what proves the value of used methods and conforms to the hypothesis of lognormal distribution of the studied combination. The limits of the suggests methodology are defined by the statistical data and the validity of the choice of particular innovation activity indicators.

\section{VIII.CONCLUSION}

According to the performed analysis it is possible to make a range of practical recommendations for providing the innovation development of the Russian regions:

- It is necessary to conduct constant monitoring of various aspects of regions' innovative activity;

- A lot of Russian regions have to pay more attention to the development of the innovational sphere and commercialization of scientific and technical innovations;

- It is expedient to use the offered complex approach for objective evaluation of the innovational processes in regions.

The results of the study can serve as a basis for periodic monitoring of the innovation activity development. Additionally, it also possible to devise the methodology of indicator construction, in particular, by using the principal 
component analysis and principal factor analysis. Thus, this will increase the quality of survey results.

\section{References}

[1] Marina I Akhmetova, "Assesment of territorial innovative system development level within socioeconomic environment", Actual Problems of Economics, 162(12), p. 260-270, 2014.

[2] Mingguang Liu., Gaoyang Li. "Comparative Research of Typical Innovation Index Compilation Method at. Domestic and Abroad.". 3rd International Conference On Information Management (ICIM), 2017

[3] Cornell University, INSEAD, and WIPO (2016): The Global Innovation Index 2016: Winning with Global Innovation, Ithaca, Fontainebleau, and Geneva.

[4] Michelle Jamrisko, Wei Lu. These Are the World's Most Innovative Economies [E-source].

Access https://www.bloomberg.com/news/articles/2017-01-17/sweden-gainssouth-korea-reigns-as-world-s-most-innovative-economies (Accessed: 01.05.2017).
[5] Gulnara Abdrakhmanova, Leonid Gokhberg, Kirill Ditkovsky, Ekaterina Islankina, Alexey Kindras, Galina Kovaleva,Natalia Kovaleva, Vera Kuznetsova, Irina Kuznetsova, Gleb Kuzmin, Evgeny Kutsenko, Dmitry Martynov,Svetlana Martynova, Elena Nechaeva, Tatyana Ratay, Galina Sagieva, Svetlana Fridlyanova, and Konstantin Fursov, "Russian Regional Innovation Development Rating. Issue 4 / L. Gokhberg (ed.); National Research University Higher School of Economics. - Moscow: HSE, 2016.

[6] Ranking of innovational development of regions [E-source]. Access: http://www.i-regions.org/regions/proekty/rejting-innovatsionnogorazvitiya (Accessed: 19.03.2018).

[7] A. Chub, "The integral indicator of the sustainable development of the regional socio-economic systems: the structure, the methodology of the formation, the direction of the application", Life Since Journal, 11(8), p 177-183, 2014

[8] Valeria A. Arsenyeva1, Svetlana A. Litvinova1, Valentina N. Parakhina, Zinaida N. Kozenko, Mikhail Y. Denisov "Innovational Development for Transitional Economy - Russia Case Study", Contemporary Economics, 10 (4), p 373-380, 2016 
TABLE I. ANNEX. INDICES OF INNOVATION ACTIVITY IN THE RUSSIAN REGIONS

\begin{tabular}{|c|c|c|c|}
\hline № & Russian regions & $\begin{array}{c}\text { Indices of } \\
\text { innovation } \\
\text { activity }\end{array}$ & Cluster \\
\hline 1 & Moscow & 0,837 & A \\
\hline 2 & Saint-Petersburg & 0,725 & A \\
\hline 3 & Republic of Tatarstan & 0,668 & A \\
\hline 4 & Nizhny Novgorod region & 0,642 & $\mathrm{~B}$ \\
\hline 5 & Moscow region & 0,622 & $\mathrm{~B}$ \\
\hline 6 & Sverdlovsk region & 0,602 & $\mathrm{~B}$ \\
\hline 7 & Perm Krai & 0,589 & $\mathrm{~B}$ \\
\hline 8 & Tomsk region & 0,588 & B \\
\hline 9 & Krasnoyarsk Krai & 0,577 & $\mathrm{~B}$ \\
\hline 10 & Novosibirsk region & 0,572 & $\mathrm{~B}$ \\
\hline 11 & Rostov region & 0,552 & $\mathrm{~B}$ \\
\hline 12 & Republic of Bashkortostan & 0,545 & $\mathrm{~B}$ \\
\hline 13 & Tumen region & 0,545 & $\mathrm{C}$ \\
\hline 14 & Voronezh region & 0,543 & $\mathrm{~B}$ \\
\hline 15 & Samara region & 0,542 & B \\
\hline 16 & Kaluga region & 0,535 & $\mathrm{~B}$ \\
\hline 17 & Khabarovsk Krai & 0,531 & $\mathrm{C}$ \\
\hline 18 & Chelyabinsk region & 0,519 & $\mathrm{~B}$ \\
\hline 19 & Yaroslavl region & 0,517 & $\mathrm{~B}$ \\
\hline 20 & Vladimir region & 0,516 & $\mathrm{~B}$ \\
\hline 21 & Irkutsk region & 0,504 & $\mathrm{~B}$ \\
\hline 22 & Chuvash Republic & 0,496 & $\mathrm{C}$ \\
\hline 23 & Magadan region & 0,496 & $\mathrm{C}$ \\
\hline 24 & Tulsk region & 0,491 & $\mathrm{C}$ \\
\hline 25 & Ulyanovsk region & 0,488 & $\mathrm{~B}$ \\
\hline 26 & Ryazan region & 0,483 & $\mathrm{C}$ \\
\hline 27 & Penza region & 0,480 & $\mathrm{C}$ \\
\hline 28 & Belgorod region & 0,478 & $\mathrm{D}$ \\
\hline 29 & Omsk region & 0,476 & $\mathrm{C}$ \\
\hline 30 & Stavropol Krai & 0,475 & $\mathrm{C}$ \\
\hline 31 & Saratov region & 0,474 & $\mathrm{C}$ \\
\hline 32 & Republic of Mordovia & 0,459 & $\mathrm{C}$ \\
\hline 33 & Murmansk region & 0,454 & $\mathrm{D}$ \\
\hline 34 & Novgorod region & 0,452 & $\mathrm{~B}$ \\
\hline 35 & Leningrad region & 0,449 & $\mathrm{C}$ \\
\hline 36 & Sevastopol & 0,449 & $\mathrm{D}$ \\
\hline 37 & Kursk region & 0,443 & $\mathrm{D}$ \\
\hline 38 & Orenburg region & 0,442 & $\mathrm{C}$ \\
\hline 39 & Smolensk region & 0,437 & $\mathrm{D}$ \\
\hline
\end{tabular}

\begin{tabular}{|c|c|c|c|}
\hline 40 & Volgograd region & 0,436 & $\mathrm{C}$ \\
\hline 41 & Lipetsk region & 0,435 & $\mathrm{C}$ \\
\hline 42 & Krasnodar Krai & 0,434 & $\mathrm{D}$ \\
\hline 43 & Tambov region & 0,432 & $\mathrm{C}$ \\
\hline 44 & Kamchatka Krai & 0,427 & $\mathrm{D}$ \\
\hline 45 & Sakhalin region & 0,426 & $\mathrm{C}$ \\
\hline 46 & Udmurt Republic & 0,426 & $\mathrm{C}$ \\
\hline 47 & Altai Krai & 0,424 & $\mathrm{C}$ \\
\hline 48 & Sakha (Yakutia) Republic & 0,424 & $\mathrm{D}$ \\
\hline 49 & Astrakhan region & 0,418 & $\mathrm{C}$ \\
\hline 50 & Primorsky Krai & 0,415 & $\mathrm{D}$ \\
\hline 51 & Republic of Karelia & 0,413 & $\mathrm{D}$ \\
\hline 52 & Kemerov region & 0,402 & $\overline{\mathrm{D}}$ \\
\hline 53 & Chukotka Autonomous Okrug & 0,401 & D \\
\hline 54 & Komi Republic & 0,400 & $\mathrm{D}$ \\
\hline 55 & Arkhangelsk region & 0,397 & $\mathrm{D}$ \\
\hline 56 & Kaliningrad region & 0,392 & $\mathrm{D}$ \\
\hline 57 & Bryansk region & 0,391 & $\mathrm{C}$ \\
\hline 58 & Ivanovsk region & 0,390 & $\overline{\mathrm{D}}$ \\
\hline 59 & Kirov region & 0,389 & $\mathrm{D}$ \\
\hline 60 & Republic of Buryatia & 0,387 & $\overline{\mathrm{D}}$ \\
\hline 61 & Republic of Crimea & 0,384 & $\mathrm{D}$ \\
\hline 62 & Orlov region & 0,384 & $\mathrm{D}$ \\
\hline 63 & Tver region & 0,381 & $\mathrm{D}$ \\
\hline 64 & Amur region & 0,366 & $\mathrm{C}$ \\
\hline 65 & Mari El Republic & 0,360 & $\mathrm{C}$ \\
\hline 66 & Vologodsk region & 0,355 & $\mathrm{C}$ \\
\hline 67 & Zabaykalsky Krai & 0,353 & $\mathrm{C}$ \\
\hline 68 & Kostroma region & 0,351 & $\mathrm{C}$ \\
\hline 69 & Karachay-Cherkess Republic & 0,349 & $\mathrm{D}$ \\
\hline 70 & Altai Republic & 0,344 & D \\
\hline 71 & Republic of Adygea & 0,333 & $\mathrm{C}$ \\
\hline 72 & Republic of North-Ossetia - Alania & 0,330 & D \\
\hline 73 & Republic of Ingushetia & 0,329 & $\overline{\mathrm{D}}$ \\
\hline 74 & Republic of Kalmykia & 0,325 & D \\
\hline 75 & Republic of Dagestan & 0,306 & $\mathrm{D}$ \\
\hline 76 & Kabardino-Balkar Republic & 0,304 & $\mathrm{D}$ \\
\hline 77 & Pskov region & 0,302 & $\mathrm{D}$ \\
\hline 78 & Tuva Republic & 0,302 & $\mathrm{D}$ \\
\hline 79 & Republic of Khakassia & 0,286 & $\mathrm{D}$ \\
\hline 80 & Kurgan region & 0,286 & $\overline{\mathrm{D}}$ \\
\hline 81 & Chechen Republic & 0,240 & $\mathrm{D}$ \\
\hline 82 & Jewish Autonomous Oblast & 0,227 & $\mathrm{D}$ \\
\hline
\end{tabular}

